\title{
Re-endodontic Management of a Five-canal Mandibular Molar with Associated Pathology: A Case Report
}

\author{
Kishan Agarwal ${ }^{1}$, Praveen S Samant ${ }^{2}$, Ayush R Singh ${ }^{3}$, Ajay Paliwal ${ }^{4}$, Sonali Jain ${ }^{5}$
}

\begin{abstract}
Aim and objective: Non-surgical re-endodontic treatment is a treatment of choice for failed root canal cases.

Background: Improper and inadequate knowledge of the root canal system ends up in a poor prognosis of root canal system. Mandibular molars have been reported with wide numbers of morphologic variations.

Case description: This article reports a case of failed root canal treatment of mandibular molar and its retreatment with successful outcomes after negotiating missed canals.

Conclusion: Little attention to possible root canal variations not only improves the finesse of the endodontic quality but also maximizes the success.

Keywords: Endodontic treatment, Mandibular molars, Middle mesial, Retreatment, Variations.

International Journal of Experimental Dental Science (2020): 10.5005/jp-journals-10029-1213
\end{abstract}

\section{BACKGROUND}

The aim of root canal treatment is thorough chemomechanical debridement of the entire pulpal cascade and finally filling it with an inert material. ${ }^{1}$ The prime requisites for any therapeutic treatment are accurate diagnosis, sound knowledge of the biological principles, and excellent execution of the treatment. ${ }^{2}$ Likewise, in endodentistry, variations in root canal anatomy present interesting challenges to successful endodontic therapy. ${ }^{3}$ Inadequate shaping and cleaning of root canal system lead to pathology and ultimately failure. ${ }^{4,5}$ The variations in teeth have been widely reported and the clinicians must have comprehensive knowledge about it. ${ }^{2}$

Most often, mandibular first molars require endodontic treatment because it is the first permanent tooth to erupt in the oral cavity. The mandibular first molars usually have two roots, one mesial and one distal, with two canals in the mesial root and with one or two canals in the distal root. $^{6}$ Occasionally, an additional root canal system known as an accessory mesial canal, is found in the mesial root of the permanent mandibular first molar which has a prevalence rate of $1-15 \% .^{7-9}$ This accessory canal is found to be located in the developmental groove between the mesiobuccal and mesiolingual root canal systems. ${ }^{7}$ Vertucci studied and reported that in the distal root, $15 \%$ had two canals at the apex and $85 \%$ had one canal; in the mesial root, $40 \%$ had one canal at the apex, $59 \%$ had two canals at the apex, $1 \%$ had three canals. ${ }^{1}$ Either mesial canals are present separately ${ }^{8,10-12}$ or can join into two and exit with two apical foramina. ${ }^{9,13-15}$ Rare findings of four canals in the mesial root have also been reported. ${ }^{16,17}$

Any form of magnification aid and ultrasonic tips or long shank round burs can be used to visualize and carefully remove the dentinal strip; respecting the pulp chamber floor to find identify orifices.

In this case report, root canal therapy has done previously failed because of missed canals in the mesial and distal root. During retreatment, all the canals were negotiated, cleaned, and filled properly.

\begin{abstract}
${ }^{1}$ Department of Conservative Dentistry and Endodontics, Lucknow, Uttar Pradesh, India

${ }^{2-5}$ Department of Conservative Dentistry and Endodontics, Saraswati Dental College and Hospital, Lucknow, Uttar Pradesh, India

Corresponding Author: Kishan Agarwal, Department of Conservative Dentistry and Endodontics, MDS, Lucknow, Uttar Pradesh, India, Phone: +91 9864513131, e-mail: kishan25021991@gmail.com

How to cite this article: Agarwal K, Samant PS, Singh AR, et al. Reendodontic Management of a Five-canal Mandibular Molar with Associated Pathology: A Case Report. Int J Experiment Dent Sci 2020;9(2):77-80.
\end{abstract}

Source of support: Nil

Conflict of interest: None

\section{Case Description}

A 25-year-old male patient reported in the Department of Conservative Dentistry and Endodontics, Saraswati Dental College, Lucknow, with a chief complaint of spontaneous pain in the lower right tooth back region. In dental history, the patient gives a history of root canal treatment done 1 year ago. There was no contributory medical history associated. On clinical examination, dislodged restoration of tooth \#46 was seen. The tooth was sensitive to percussion and palpation. "The preoperative radiograph of tooth \#46 revealed faulty root canal treatment associated periapical lesion" (Fig. 1). The diagnosis of the case was exacerbating apical periodontitis associated with incomplete root canal treatment.

Non-surgical endodontic therapy was decided after having patients' consent. After administration of $2 \%$ lignocaine with adrenaline, the tooth was isolated under a rubber dam. "Previous coronal filling was removed and access cavity was re-shaped using a tungsten carbide bur. The root canal fillings were removed with Hedstrom files" (Fig. 2). Troughing was carried out using a P5 


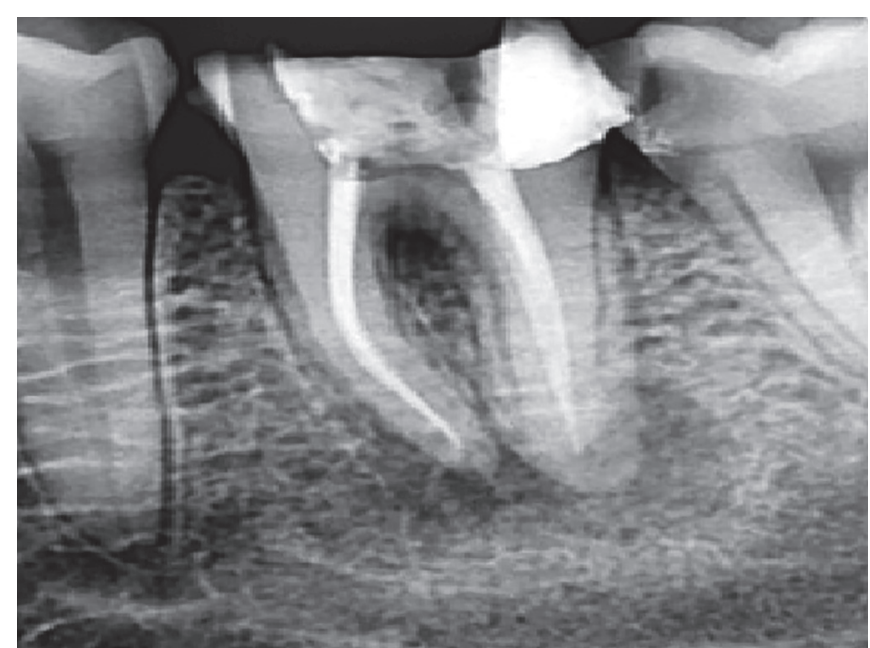

Fig. 1: Preoperative radiograph showing faulty root canal restoration with the associated radiolucent area around root apex \#46

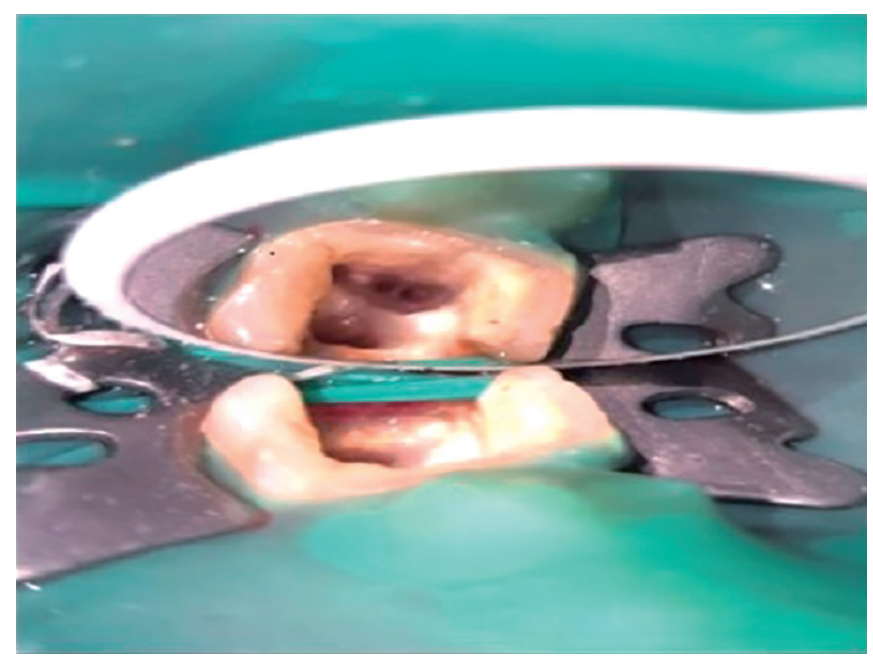

Fig. 3: Pulp chamber showing the three orifices in the mesial end and two orifices in distal end \#46

Booster (Satelec) ultrasonic unit and ultrasonic tip ET-20D (Satelec). "On examination of pulp chamber under a magnifying loupe, an interconnecting groove was observed between mesiolingual and mesiobuccal canal, with a catch point present. The loupe revealed the extracanal, i.e., middle mesial canal orifice" (Fig. 3). During the previous root canal treatment, the middle mesial canal was not instrumented. "Working length was determined using a standard radiographic record", (Fig. 4) and later confirmed with an apex locator (Denta Port; J. Morita Mfg Corp., Kyoto, Japan). A ProTaper NiTi rotary instrument (Dentsply Maillefer, Ballaigues, Switzerland) was used for cleaning and shaping of the canals. All root canals were irrigated with $5.25 \%$ sodium hypochlorite followed by $17 \%$ EDTA. After drying the canals with a paper point, calcium hydroxide was placed in the canals and a temporary dressing was given.

After 2 weeks, the tooth was found to be asymptomatic. "Before master-cone radiograph, final ultrasonically activated irrigation accompanied with $5.25 \% \mathrm{NaOCl}$ and $17 \%$ EDTA irrigation was carried off" (Fig. 5). "Root canals were obturated by cold lateral compaction of gutta-percha and AH Plus sealer" (Fig. 6).

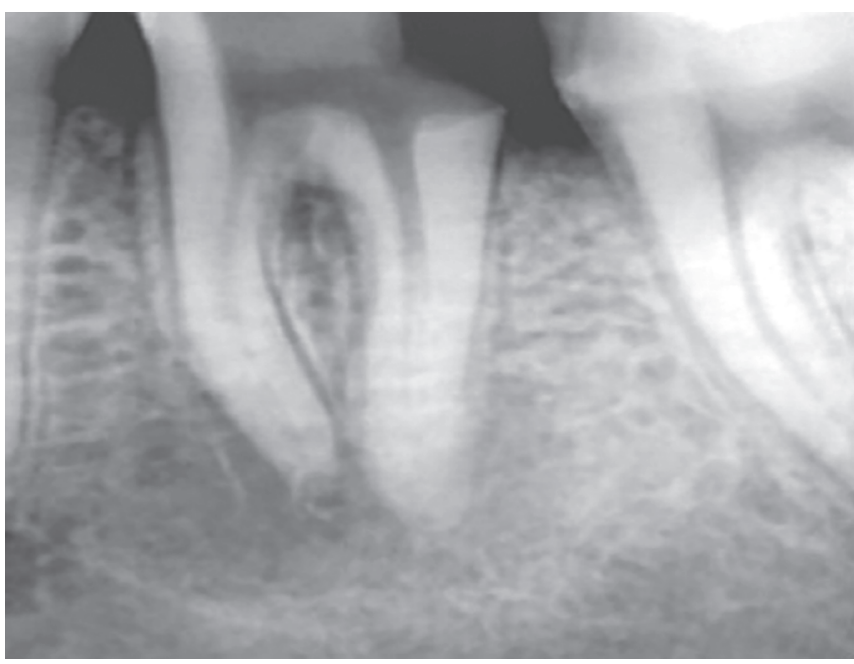

Fig. 2: After removal of previous root filling material \#46

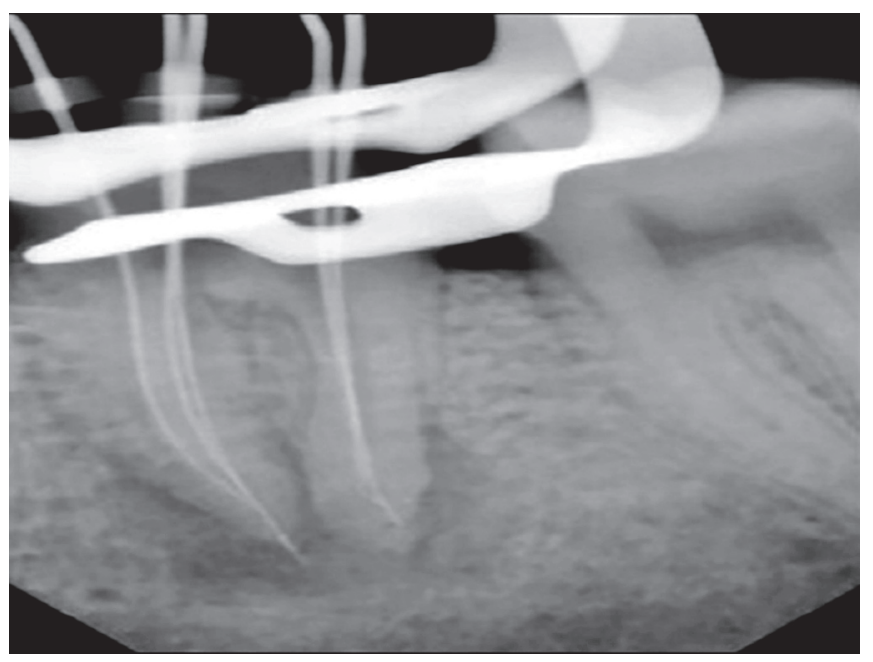

Fig. 4: Working length radiograph \#46

\section{Discussion}

Successful endodontic therapies rely upon many factors, the most important step is having sound background information of the internal anatomy of teeth and their probable variations. This information is essential because it influences and establishes the efficacy of all the succeeding procedures, which includes the location of canals, chemomechanical debridement, creation of space for the medicament delivery, and optimized canal configuration for adequate obturation. ${ }^{6}$ Anatomical variations are challenges that are often encountered by clinicians while performing endodontic treatment. In this case report, an accessory middle mesial canal was left untreated during previous endodontic therapy which probably harbored necrosed tissue, bacteria, and related irritants that must have inevitably contributed to clinical symptoms and the periapical pathology of endodontic origin. ${ }^{18,19}$

According to Pomeranz et al., the middle mesial is classified into three categories. First, when the instrument moves freely between the mesiobuccal and mesiolingual canals and middle mesial canal, it is termed as "fin"; second, when prepared canal 


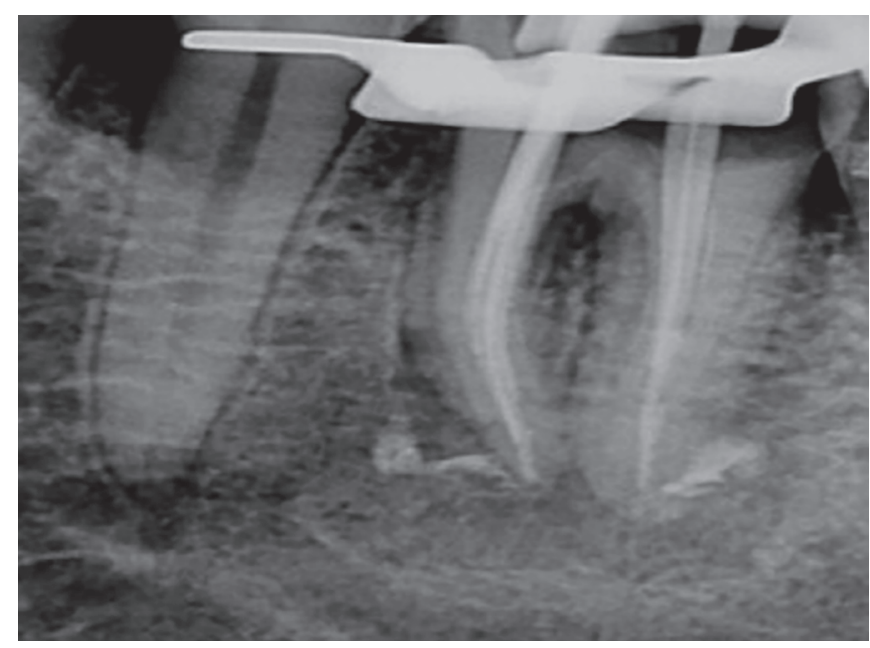

Fig. 5: Master cone radiograph \#46

originates as a separate orifice but joins apically to a mesiobuccal or mesiolingual canal, it is called "confluent"; and third, when it originates and terminates from the separate orifice and separate foramen, respectively, it is termed as "independent". ${ }^{10}$ In this case, the middle mesial was a confluent type because it originated as a separate orifice and then joined mesiolingual at its middle third.

With the development of teeth, root canal morphology changes take place. In young and elderly age, intracanal communications prevalence was low whereas, in the intermediate age group, this prevalence was high. It has been reported that young individuals have high pulp horns and large single root canals but with age, there are regressive changes noticed with secondary dentin deposition resulting in the formation of partitions or separate canals and transverse connecting systems. ${ }^{6}$

Due to the complex canal system, this case was completed in multiple visits. ${ }^{20}$ It has been illustrated in many studies that in cases of re-treatment, disinfecting the canal with sodium hypochlorite helped in the elimination of microbes. ${ }^{21}$

Unusual root anatomy and periodontal ligament outlines should be evaluated meticulously from radiographs. A conventional technique for assessing unusual anatomy includes the use of certain dyes, performing Champagne bubble test, manual inspection of the floor with explorer. ${ }^{22}$

Between mesiobuccal and mesiolingual orifices in the pulp chamber, on careful examination, a classical white line is seen which must be further explored with small hand files for a catch.

The new genera are all about magnification which allows a better and closer view of the field. Dental operating microscope and dental loupe serve as magnifications tools in assessing aberrant canal orifices in the operating field. ${ }^{23}$ In the present case, the entire case was performed using a dental loupe and concomitant use of ultrasonic tips for troughing the pulp chamber.

A traditional three-dimensional radiographic technique like cone-beam computed tomography is a tool of great importance in rendering the clinician with apt details of the tooth anatomy. Kamble et al. reported that $\mathrm{CBCT}$ is an important aid to detect variations in the root canal morphology of teeth of both arches. ${ }^{24}$

This case had a successful outcome after retreatment of all the canals thoroughly.

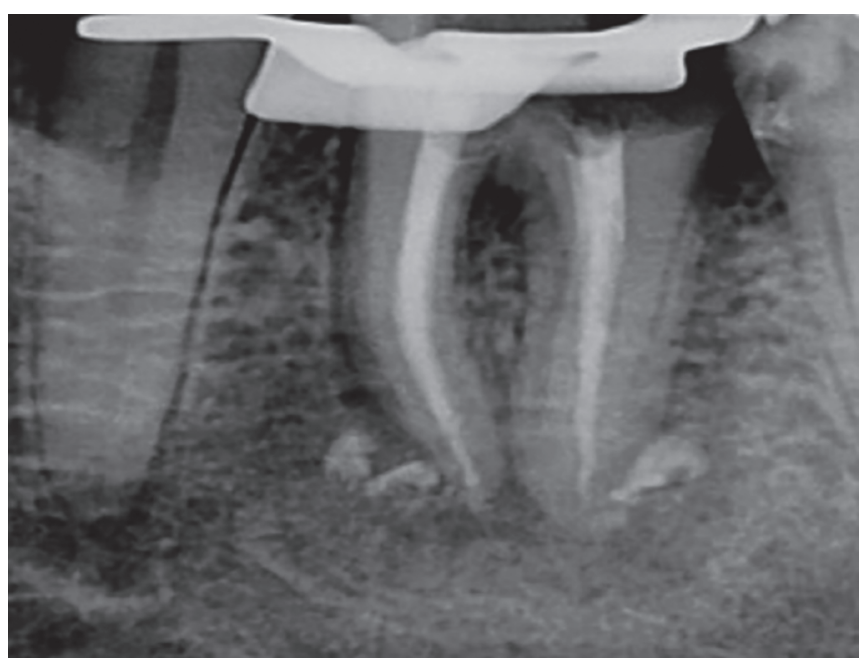

Fig. 6: Post-obturation radiographic representation \#46

\section{Conclusion}

Clinicians while performing endodontic therapy should be aware of all possible variations and should search for hidden canals with adequate magnification aids for better visualization.

\section{Clinical Significance}

With an increasing number of endodontic treatments being done each day, it has become imperative to avoid or minimize the most fundamental of reasons leading to endodontic failure. Cleaning and shaping of all root canals are of utmost importance for its successful outcome. Variations of root canal anatomy should not be overlooked because it can be potentially responsible for case failure.

\section{ACKNOWLedgment}

I would like to acknowledge my entire team for the success of this case.

\section{References}

1. Vertucci FJ. Root canal anatomy of the human permanent teeth. Oral Surg Oral Med Oral Pathol 1984;58(5):589-599. DOI: 10.1016/00304220(84)90085-9.

2. Swartz $D B$, Skidmore $A E$, Griffin JA. Twenty years of endodontic success and failure. J Endod 1983;9(5):198-202. DOI: 10.1016/S00992399(83)80092-2.

3. Ingle Jl. Endodontics. 3rd ed., Philadelphia: Lea \& Febiger; 1985. p. 37.

4. Cleghorn BM, Goodacre CJ, Christie WH. Morphology of teeth and their root canal systems. In: Ingle Jl, Bakland LK, Baumgartner JC. Ingle's Endodontics. 6th ed., Hamilton, Ontario: B C Decker Inc; 2008. pp. 151-220.

5. Christie WH, Peikoff MD, Fogel HM. Maxillary molars with two palatal roots: a retrospective clinical study. J Endod 1991;17(2):80-84. DOI: 10.1016/S0099-2399(06)81613-4.

6. Deepalakshmi M, Anupama R, Khan HS. The mandibular first molar with three canals in the mesial root - a case report. J Clin Diagn Res 2013;7:601-603. DOI: 10.7860/JCDR/2013/4234.2835.

7. Goel NK, Gill KS, Taneja JR. Study of root canal configuration in mandibular first permanent molars. J Indian Soc Pedod Prev Dent 1991;8:12-14. 
8. Wasti F, Shearer AC, Wilson NH. Root canal systems of the mandibular and maxillary first permanent molar teeth of South Asian Pakistanis. Int Endod J 2001;34(4):263-266. DOI: 10.1046/j.13652591.2001.00377.x.

9. Baugh D, Wallace J. Middle mesial canal of the mandibular first molar: a case report and literature review. J Endod 2004;30(3):185-186. DOI: 10.1097/00004770-200403000-00015.

10. Pomeranz HH, Eidelman DL, Goldberg MG. Treatment considerations of the middle mesial canal of mandibular first and second molars. J Endod 1981;7(12):565-568. DOI: 10.1016/S0099-2399(81) 80216-6.

11. Campos FH. Three canals in the mesial root of mandibular first permanent molars: a clinical study. Int Endod J 1989;22(1):39-43. DOI: 10.1111/j.1365-2591.1989.tb00503.x.

12. Gulabivala K, Aung TH, Alavi A, et al. Root and canal morphology of Burmese mandibular molars. Int Endod J 2001;34(5):359-370. DOI: 10.1046/j.1365-2591.2001.00399.x.

13. Ricucci D. Three independent canals in the mesial root of a mandibular first molar. Endod Dent Traumatol 1997;13(1):47-49. DOI: 10.1111/ j.1600-9657.1997.tb00010.x.

14. DeGrood ME, Cunningham CJ. Mandibular molar with five canals: Report of a case. J Endod 1997;23(1):60-62. DOI: 10.1016/S00992399(97)80211-7.

15. Jacobsen EL, Dick K, Bodell R. Mandibular first molars with multiple mesial canals. J Endod 1994;20(12):610-613. DOI: 10.1016/S00992399(06)80088-9.
16. Reeh ES. Seven canals in a lower first molar. J Endod 1998;24(7):497499. DOI: 10.1016/S0099-2399(98)80055-1.

17. Kontakiotis EG, Tzanetakis GN. Four canals in the mesial root of a mandibular first molar. A case report under the operating microscope. Aust Endod J 2007;33(2):84-88. DOI: 10.1111/j.1747-4477.2007.00068.x.

18. Sjogren U, Haggalund B, Sundqvist $G$, et al. Factors affecting the longterm results of endodontic treatment. J Endod 1990;16(10):498-504. DOI: 10.1016/S0099-2399(07)80180-4.

19. Cohen S, Burns RC. Non-surgical endodontic treatment. Pathways of the pulp. 8th ed., St. Louis: Mosby; 2002. pp. 875-929.

20. Lin LM, Lin J, Rosenberg PA. One appointment endodontic therapy: biological considerations. J Am Dent Assoc 2007;138(11):1456-1462. DOI: 10.14219/jada.archive.2007.0081.

21. Haapasalo M, Endal U, Zandi $\mathrm{H}$, et al. Eradication of endodontic infection by instrumentation and irrigation solutions. Endodontic Topics 2005;10(1):77-102. DOI: 10.1111/j.1601-1546.2005.00135.x.

22. Penukonda R, Saraf PA, Patil TN, et al. A clinical approach to the successful management of variations of middle mesial canals: a case series. Saudi Endod J 2018;8(2):139-143. DOI: 10.4103/sej.sej_13_17.

23. Aminsobhani M, Shokouhinejad N, Ghabraei S, et al. Retreatment of a 6-canalled mandibular first molar with four mesial canals: a case report. Iran Endod J 2010;5:138-140.

24. Kamble AP, Pawar RR, Mattigatti S, et al. Cone-beam computed tomography as advanced diagnostic aid in endodontic treatment of molars with multiple canals: two case reports. J Conserv Dent 2017;20(4):273-277. DOI: 10.4103/0972-0707.219194. 